\title{
Carbon Emission Reduction Performance of Green Biased Technology Progress: From the Perspective of Industrial Structure Adjustment
}

\author{
Yang $\mathrm{Li}^{1, *}$ \\ ${ }^{1}$ International Business School, Shaanxi Normal University, 710119, Xi’an, China
}

\begin{abstract}
This paper uses China's provincial panel data from 1997 to 2015 to construct the MalmquistLuenberger productivity indicators to measure the level of green biased technology progress, and measures the change in industrial structure based on indicators of low-carbon transformation, optimization and rationalization of industrial structure, and empirically tests the impact of green biased technology progress and industrial structure adjustment on China's provincial carbon emission intensity. The results show that green biased technology progress can significantly exert the suppression effect of carbon emission intensity through the channel of low-carbon transformation of industrial structure.
\end{abstract}

\section{Introduction}

China is the world's largest source of carbon emissions, and the central government pledged in the Paris Agreement to reduce its carbon intensity by $60-65$ percent by 2030 from 2005 levels. The report of the 19th National Congress of the Communist Party of China outlines a roadmap for China's ecological civilization construction and green development, which closely integrates the concepts of technological progress, industrial structure adjustment and ecological environment, highlighting the key themes of China's future development. The interdisciplinary research of endogenous growth theory and environmental science points out that if technological progress has specific biased characteristics among different types of technologies such as cleanliness or pollution, it will cause changes in the industrial structure in the direction that is favorable to or unfavorable to green development, and eventually lead to differentiated environmental performance. Therefore, studying the relationship between green-biased technological progress, industrial structure adjustment and carbon emission reduction will help solve the current incoordination of economic growth and climate environment, and has rich practical significance and policy value.

Through literature review, it is found that changes in industrial structure and technological progress are recognized factors with potential for carbon emission reduction. Regarding the technological progress factor, represented by the carbon emission accounting and prediction carried out by international authoritative research institutions (such as IPCC), it points out the contribution rate of different types of technological progress and development to carbon emission reduction, and the contribution rate of technological progress factors ranks first among all factors[1].Studies have also pointed out that technological advancement factors have a very limited effect on curbing China's current carbon emissions[2]. Similar to the factors of technological progress, the impact of changes in industrial structure on carbon emissions can also be positive or negative. When the industrial structure develops in the direction of high energy consumption and high pollution, the carbon emission performance of the economy is usually low[3]; and the structural adjustment from high-carbon industry dominance to low-carbon industry dominance reflects the process of low-carbon industrial structure and can produce carbon emission reduction effects [4].

Existing research on the impact of technological progress and industrial restructuring on carbon emissions has not yet been fully unified. Research hotspots focus on the independent effects of various carbon emissions influencing factors. In fact, these factors are not isolated in the "economy-environment" system. Studies have shown that technological progress is an important factor in the green transformation of my country's industry [5]. Although the synergistic impact of technological progress and industrial structure adjustment on carbon emissions is important, it lacks in-depth discussion [6]. In addition, the endogenous growth theory believes that the cleanliness or pollution bias of technological progress directly promotes changes in environmental performance, and the adjustment of industrial structure plays a key role in it. This indicates that the impact of technological progress on carbon emissions partly depends on whether the industrial structure evolves in a direction conducive to energy saving, emission reduction and green development. Specifically, green-biased technological progress will cause adjustments in the industrial structure, increasing the output ratio of the clean sector relative to the polluting

* Corresponding author: shiyangwe@163.com 
sector, and a clean industrial structure can achieve the same total economic growth with a lower increase in carbon emissions, and then reduce the carbon emission intensity per unit of total economic output. Therefore, this paper takes the influencing factors of carbon emission intensity as the research object, and examines the independent influence and joint effect of green technological progress and industrial structure adjustment on carbon emission.

\section{Method and Date}

\subsection{Econometric Model}

This paper first builds the following basic models of the factors affecting carbon intensity:

$$
\ln c p y_{i t}=\xi_{0}+\xi_{1} g p_{i t}+\xi_{2} \ln c p y_{i t-1}+\xi_{j}^{\prime} Z_{i t, j}^{\prime}+\psi_{i t}
$$

On the basis of equation(1), industrial structure adjustment variables are added to construct the following mediating effect model:

$$
\begin{aligned}
& \ln c p y_{i t}=\alpha_{0}+\rho_{1} A G P I_{i t}+\rho_{2} L C S_{i t}+\rho_{3} T S R_{i t}+\rho_{4} T L A_{i t} \\
& +\rho_{5} \ln c p y_{i t-1}+\rho_{\mathrm{j} j}^{\prime} Z_{i t, j}^{\prime}+\mu_{i t} \\
& L C S_{i t}=\alpha_{1}+\omega_{1} A G P I_{i t}+\omega_{2} L C S_{i t-1}+\omega_{\mathrm{j}}^{\prime} Z_{i t, j}^{\prime}+\mu_{i t}^{\prime} \\
& T S R_{i t}=\alpha_{2}+\varphi_{1} A G P I_{i t}+\varphi_{2} T S R_{i t-1}+\varphi_{j}^{\prime} Z_{i t, j}^{\prime}+\mu_{\mathrm{it}}^{\prime \prime} \\
& T L A_{i t}=\alpha_{3}+\gamma_{1} A G P I_{i t}+\gamma_{2} T L A_{i t-1}+\gamma_{j}^{\prime} Z_{i t, j}^{\prime}+\mu_{\mathrm{it}}^{\prime \prime}
\end{aligned}
$$

where lncpy denotes carbon emission intensity. $g p$ denotes the level of green-biased technological progress. LCS,TSR and TLA denotes industrial structure adjustment variables, which are low-carbon transformation of industrial structure, optimization of industrial structure and rationalization of industrial structure; $Z_{j}$ denotes control variables, including $\ln g d p$ (the variable of economic scale and its quadratic polynomial); gov (government expenditures other than expenditures on science, education, culture and health as a percentage of GDP) represents the degree of government economic intervention; lninfra (highway mileage per unit area) represents the situation of regional infrastructure; fdirate (the actual use of foreign capital as a percentage of GDP) represents the level of economic openness; urban (proportion of non-agricultural population) represents the level of urbanization; rdrate (R\&D expenditure as a percentage of GDP ) represents the intensity of research and development. Considering the endogenous problem caused by the lagging first-order explained variable, the system GMM method is used to estimate the parameters of the dynamic panel model.

\subsection{Measurements of Green Biased Technology Progress}

This paper refers to related literature[7], adopts the Malmquist-Luenberger productivity function, considers the undesired output of carbon emissions under the traditional input-output relationship, and uses the cumulative green productivity index to measure the level of green-biased technological progress.
First, referring to Oh's research plan[8], we construct the following green productivity index:

$$
\operatorname{GPI}^{t, t+1}\left(x^{t}, y^{t}, b^{t}, x^{t+1}, y^{t+1}, b^{t+1}\right)=\frac{1+D^{G}\left(x^{t}, y^{t}, b^{t}\right)}{1+D^{G}\left(x^{t+1}, y^{t+1}, b^{t+1}\right)}
$$

Regarding China's 30 provincial-level units as decision-making units, it is assumed that there are $N$ types of inputs $x=\left(x_{1}, x_{2}, \cdots, x_{N}\right) \in R_{N}^{+}, M$ types of willing outputs $y=\left(y_{1}, y_{2}, \cdots, y_{M}\right) \in R_{M}^{+}$, and $I$ type of unwilling outputs $b=\left(b_{1}, b_{2}, \cdots, b_{I}\right) \in R_{I}^{+}$in the economic production process. We set capital stock (calculated based on the perpetual inventory method and 1997 constant prices), labor and energy consumption as input variables, and real GDP (calculated at 1997 constant prices) as expected output, and carbon dioxide emissions is the unexpected output. $D^{G}$ is the directional distance function of production activities in each province, defined as follows:

$$
D^{G}\left(x^{t}, y^{t}, b^{t}\right)=\max \left\{\beta \mid(y+\beta y, b-\beta b) \in P^{G}(x)\right\}
$$

where $P^{G}=$ convex $\left(P^{1} \cup P^{2} \cup \ldots \cup P^{T}\right)$ is an overall benchmark production technology, and $P^{t}$ is the current benchmark production technology, that is

$$
P^{t}\left(x^{t}\right)=\left\{\left(y^{t}, b^{t}\right) \mid x^{t} \text { produce }\left(y^{t}, b^{t}\right)\right\}, \mathrm{t}=1,2, \ldots \mathrm{T} \text {. }
$$

Based on the green productivity index, we construct a cumulative green productivity index:

$$
A G P I^{t, t+1}=A G P I^{t-1, t} \times G P I^{t, t+1} \text { if } t>1
$$

We set the initial value of $A G P I$ to 1 . The higher the $A G P I$ value, the more sustained growth in the green productivity index of the corresponding province, and its input-output relationship shows features that are conducive to suppressing carbon emissions.

\subsection{Measurements of Industrial Structure Adjustment}

(1) Index of low-carbon transformation of industrial structure[9]:

$$
L C S_{i t}=\sum_{j}^{n} Y_{i t, j}^{l c} / \sum_{k}^{m} Y_{i t, k}^{h c}
$$

where $Y^{l c}{ }^{l t, j}$ denotes the output value of the $\mathrm{j}$-th (total number is $\mathrm{n})$ low-emission intensity industry, $Y_{i t, k}^{h c}$ denotes the output value of the $\mathrm{k}$-th (total number is $\mathrm{m}$ ) high-emission intensity industry. The increase in the value of $L C S$ means that low-carbon industries in the province are replacing high-carbon industries, that is, the degree of low-carbon transformation of industrial structure is rising.

(2) Index of optimization of industrial structure[10]:

$$
T S R_{i t}=Y_{i t}^{t e r} / Y_{i t}^{\mathrm{sec}}
$$

where $Y_{i t}^{\text {ter }}$ is the output value of the tertiary industry; $Y_{i t}^{\text {sec }}$ is the output value of the secondary industry. The increase in the value of TSR reflects the upgrading of the industrial structure of the economy[8].

(3) Index of rationalization of industrial structure: Referring to Gan C.H.et al.[10], we construct the following cubic industrial structure rationalization $(T L)$ 
index:

$$
T L_{i t}=\sum_{j}^{n=3}\left(\frac{Y_{i t, j}}{Y_{i t}}\right) \ln \left(\frac{Y_{i t, j}}{L_{i t, j}} / \frac{Y_{i t}}{L_{i t}}\right)
$$

where $Y_{i t, j}$ and $L_{i t, j}$ are the output value and the number of employees in the j-th industry, $Y_{i t}$ and $L_{i t}$ are the total output value and total number of employees in all industries. If $T L$ is not zero, it means that the industrial structure deviates from the equilibrium state. Because the value range of $T L$ is [0,1], the variable $T L A=1 / T L$ is set to characterize the rationalization of the industrial structure, and the increase in the value indicates that the industrial structure tends to be balanced and reasonable.

\subsection{Data}

This article uses 30 provinces, municipalities and autonomous regions in mainland China (1) as samples from 1997 to 2015. Before the empirical analysis, this paper conducted a correlation test on the research indicators, and no extremum were found, and the Pearson correlation coefficient of the main variables was basically less than 0.6, indicating that there is no strong correlation between variables, which avoids the problem of multicollinearity to a certain extent.

\section{The Impact of Green Biased Technology Progress and Industrial Structure Adjustment on China's Provincial Carbon Emission Intensity}

Columns (1) to (5) in Table 1 respectively report the estimated results of equation (1) to (5).

Table1. Estimation results of the impact of green-biased technological progress on carbon intensity.

\begin{tabular}{|c|c|c|c|c|c|}
\hline $\begin{array}{l}\text { Explained } \\
\text { variable }\end{array}$ & $\begin{array}{c}\mathbf{( 1 )} \\
\ln c p y\end{array}$ & $\begin{array}{c}\mathbf{( 2 )} \\
\ln c p y\end{array}$ & $\begin{array}{l}\text { (3) } \\
L C S\end{array}$ & $\begin{array}{l}\mathbf{4}) \\
T S R\end{array}$ & $\begin{array}{l}\mathbf{5}) \\
T L A\end{array}$ \\
\hline$\overline{A G P I}$ & & -0.103 & $0.227^{* *}$ & 3.197 & $7.409^{* * *}$ \\
\hline & $\begin{array}{c}0.336^{* * *} \\
(0.113)\end{array}$ & $(0.256)$ & $(0.093)$ & $(2.258)$ & $(1.857)$ \\
\hline$L C S$ & & $\begin{array}{c}- \\
0.076^{* * *} \\
(0.025)\end{array}$ & & & \\
\hline$T S R$ & & $\begin{array}{l}-0.003 \\
(0.003)\end{array}$ & & & \\
\hline$T L A$ & & $\begin{array}{c}0.002 \\
(0.004)\end{array}$ & & & \\
\hline Cons & $\begin{array}{c}0.106 \\
(0.673)\end{array}$ & $\begin{array}{l}1.603^{*} \\
(0.880)\end{array}$ & $\begin{array}{l}1.592^{*} \\
(0.891)\end{array}$ & $\begin{array}{c}21.780 \\
(14.317)\end{array}$ & $\begin{array}{c}3.931 \\
(7.817)\end{array}$ \\
\hline Control variable & YES & YES & YES & YES & YES \\
\hline $\begin{array}{l}\text { Lagging } \\
\text { explained } \\
\text { variable }\end{array}$ & YES & YES & YES & YES & YES \\
\hline Observations & 510 & 450 & 510 & 510 & 450 \\
\hline Number of & 30 & 30 & 30 & 30 & 30 \\
\hline
\end{tabular}

\section{provinces}

Note: $(1)^{* * *}$ and $^{* * *}$ denote coefficient significant at $10 \%, 5 \%$, and $1 \%$, respectively; (2)Standard errors in parentheses; (3) Due to the availability of data, the time range of TLA data by province is from 1997 to 2012, so the number of observations is relatively small.

\footnotetext{
${ }^{(1)}$ Due to the availability of data and the uniformity requirements of statistical indicators, the Tibet Autonomous Region is excluded from
}

The key result of Table 1 is that green-biased technological progress has a significant negative impact on carbon emission intensity, and this impact is transmitted through low-carbon transformation of industrial structure. First of all, comparing column (2) and column (1), the coefficient of the variable $A G P I$ is no longer significant, indicating that after controlling the three industrial structure adjustment variables, the direct impact of green-biased technological progress is not significant. Its impact on carbon emission intensity is explained by the carbon intensity impact of industrial structure adjustment variables. Secondly, only the variable $L C S$ in column (2) has a carbon intensity suppression effect, indicating that low-carbon transformation of industrial structure is a potential transmission channel. Finally, in columns (3) to (5), the influence coefficients of green-biased technological progress on $L C S$ variables and $T L A$ variables are significantly positive, indicating that green-biased technological progress can significantly promote the low-carbon transformation and rationalization adjustment of industrial structure. Based on the above three points, the direct impact of green-biased technological progress on carbon intensity is not significant, and its carbon intensity suppression effect is mainly achieved through the adjustment of industrial structure to low-carbon. According to the theory of biased technological progress, the key mechanism of greenbiased technological progress lies in the relatively faster development of green and low-carbon technologies to realize the substitution of green and low-carbon production industries for polluting and high-carbon production industries. The development of the industry promotes economic growth and controls the increase in carbon emissions, thereby achieving the effect of restraining carbon intensity.

\section{Conclusions}

Based on the analysis framework of biased technological progress and China's inter-provincial panel data from 1997 to 2015, this paper uses the Malmquist-Luenberger productivity function to measure the level of green-biased technological progress in China's provinces, and constructs indicators of low-carbon transformation , optimization and rationalization of industrial structure to measure the process of industrial structure adjustment, and then studied the impact of green-biased technological progress and industrial structure adjustment on China's provincial carbon emission intensity. The research results show that the influence factors of technological progress and industrial structure of carbon emission intensity change are not completely isolated. The low-carbon adjustment of the industrial structure is an important transmission channel through which green-biased technological progress factors play a role. Therefore, in order to better fulfill the carbon emission reduction commitment, the government should focus on supporting the development of low-carbon industries, formulate differentiated industrial policies in different regions,

the provincial samples selected in this paper. 
attach importance to the conductive role of the industrial structure, and guide technological progress toward energy conservation and emission reduction. In addition, the government should start from the aspects of price, technological innovation and production factor allocation, and promote the channel role of low-carbon adjustment of the industrial structure, so as to achieve the carbon emission reduction target of the green development strategy. In short, in order to realize China's carbon emission reduction vision, the government must eliminate policy obstacles and promote the coordination of green technology policies and green industry policies.

\section{References}

1. IPCC. (2007) The Physical Science Basis of Climate change (Contribution to The Fourth Assessment Report of the International Panel on Climate Change). Geneva: International Panel on Climate Change (IPCC).

2. Qian, J. (2020) Research on the Threshold Effect of Energy Conservation-biased Technological Progress on Industrial Energy Conservation and Emission Reduction. Scientific research management, 41:223233.

3. Fu, X., Michael L. Lahr, Zhang, Y.X., Meng, B. (2018) Economic structure adjustment based on the interregional energy-carbon emissions-economic inputoccupancy-output model. Management Review, 30:207-217.

4. Wu, Z.X., Xie, X.J., Wang, S.P. (2012) Analysis of the impact of economic growth and industrial structure on carbon emissions: Based on China's interprovincial panel data. Chinese Management Science, 3: 161-166.

5. Peng, W., Xiong, K., Li, H. (2020) Environmental Decentralization, Technological Innovation, and Green Transformation of China's Industrial Industries: An Empirical Study Based on Provincial Spatial Panels. Contemporary economic management,6:1-13.

6. TSURUMI T, MANAGI S. (2010) Decomposition of the environmental kuznets curve: scale, technique, and composition effects. Environmental Economics and Policy Studies, 11:19-36.

7. ZHOU X, ZHANG J, LI J. (2013) Industrial structural transformation and carbon dioxide emissions in China. Energy Policy, 57: 43-51.

8. Oh, D.-h. (2010) A global Malmquist-Luenberger productivity index. Journal of Productivity Analysis ,34:183-197.

9. Yan, Z.M., Deng, X.L., Cheng, B.D. (2016) The impact of green technological progress on the lowcarbonization of China's industrial structure. Comparison of economic and social systems, 4: 25-39.

10. Gan, C.H., Zheng, R.G., Yu, R.G. (2011) The Impact of China's Industrial Structure Changes on Economic Growth and Volatility. Economic Research, 5: 415,31 . 